\title{
Arterial Thromboembolism Secondary to Subaortic Stenosis in a Persian Kitten
}

\author{
Alessandra Michelly Ferreira', Simone Tostes de Oliveira Stedile', \\ Vinícius Bentivóglio Costa Silva² \& Marlos Gonçalves Sousa'
}

\begin{abstract}
Background: Aortic stenosis refers to several types of anatomic and functional obstructions of the left ventricular outflow tract. In small animals, this anomaly is most commonly documented as either a congenital lesion or an obstruction that develops soon after birth. It is a hereditary disease, caused by a dominant autosomal gene and modifying genes that interfere with phenotype expression. Even though aortic thromboembolism may be a potential complication in cats with cardiac diseases, aortic stenosis is deemed rare in that species. In this paper, we report an unusual case of a Persian kitten with aortic stenosis that eventually developed arterial thromboembolism.

Case: A 7-month-old Persian kitten $(3.1 \mathrm{~kg})$ was admitted to a Veterinary Teaching Hospital with a history of hindlimbs paralysis over the past $48 \mathrm{~h}$, as well as excessive vocalization. Also, the cat presented with inappetence, adipsia, urine incontinence, and hematuria. On physical examination, we observed hypothermia and cold paws. The footpads were cyanotic and there were no palpable femoral pulses. Cardiac auscultation disclosed a regular fast pace (200 bpm) and a grade 2/6 murmur heard best over the left cardiac base, but irradiating to the contralateral hemithorax. Prothrombin time and activated partial thromboplastin time were within the normal reference range, but the complete blood count showed microcytosis, lymphopenia, and hyperproteinemia. Also, elevated alanine aminotransferase and BUN were identified. On the echocardiogram, we observed a subvalvular aortic stenosis, which resulted in concentric remodeling of the left ventricle and a mild left atrial dilation. The stenotic lesion was classified as mild. Also, the thoracic radiography unveiled cardiomegaly. The recommended therapy included atenolol $(6.25 \mathrm{mg} / \mathrm{cat} \mathrm{PO}, \mathrm{q} 24 \mathrm{~h})$, clopidogrel $(18.7 \mathrm{mg} / \mathrm{cat} \mathrm{PO}, \mathrm{q} 24 \mathrm{~h})$, enoxaparin $(1 \mathrm{mg} / \mathrm{kg} \mathrm{SC}, \mathrm{q} 24 \mathrm{~h})$, methadone $(0.2 \mathrm{mg} / \mathrm{kg} \mathrm{IM}, \mathrm{q} 8 \mathrm{~h})$ and amoxicillin + potassium clavulanate $(20 \mathrm{mg} / \mathrm{kg} \mathrm{SC}$, $\mathrm{q} 12 \mathrm{~h}$ ). Additional recommendations included physical therapy on the hindlimbs as well as monitoring heart rate and blood pressure every two hours in the first day, and every six hours thereafter during hospitalization. Seven days later, the cat was depressed, extremely lethargic, and did not respond to therapy at all. Also, necrosis was documented on the hindlimb paws. Therefore, in face of the unfavorable prognosis, the owners opted for euthanasia.

Discussion: Cats with cardiomyopathy have an increased risk for developing arterial thromboembolism. The dilated left atrium causes blood stasis and, because of the augmented sensitivity of platelets to serotonin, they aggregate and increase the likelihood of thrombi formation. While some thrombi remain within the heart, usually in the left atrial appendage, others may dislodge and follow blood flow to the aortic trifurcation down in the abdomen. That obstruction impairs blood flow to its tributaries such as the iliac and femoral arteries, which are involved with the hind limbs perfusion. Cats with severe stenotic lesions usually carry a bad prognosis, contrasting with our patient in which only a mild stenosis was documented. However, having developed aortic thromboembolism absolutely changed the prognosis for this cat Although aortic stenosis is an uncommon condition in cats, its occurrence should be considered as differential diagnosis whenever young patients are admitted with a cardiac murmur. If the diagnosis is confirmed, the patient will need periodical re-evaluations due to the possibility of complications such as arterial thromboembolism. This condition carries a bad prognosis. In this case, it was responsible for the decline in clinical condition which eventually was crucial for the owner opting to euthanize the cat.
\end{abstract}

Keywords: congenital heart disease, echocardiography, valve dysplasia, ischemia. 


\section{INTRODUCTION}

Aortic stenosis refers to several types of anatomic and functional obstructions of the left ventricular outflow tract. In small animals, this anomaly is most commonly documented as either a congenital lesion or an obstruction that develops soon after birth [1]. It is a hereditary disease, caused by a dominant autosomal gene and modifying genes that interfere with phenotype expression. Even though aortic thromboembolism may be a potential complication in cats with cardiac diseases, aortic stenosis is deemed rare in that species [9].

In this paper, we report an unusual case of a Persian kitten with aortic stenosis that eventually developed arterial thromboembolism. Also, a discussion of the clinical aspects of the disease is presented so that veterinarians become aware of its occurrence and include this anomaly in the differential diagnostic list for young cats in which a murmur has been documented.

\section{CASE}

A 7-month-old Persian kitten $(3.1 \mathrm{~kg})$ was admitted to a Veterinary Teaching Hospital with a history of hindlimbs paralysis (Figure 1) over the past $48 \mathrm{~h}$, as well as excessive vocalization. Also, the cat presented with inappetence, adipsia, urine incontinence, and hematuria. On physical examination, we observed hypothermia and cold paws. The footpads were cyanotic and there were no palpable femoral pulses. Cardiac auscultation disclosed a regular fast pace (200 bpm) and a grade 2/6 murmur heard best over the left cardiac base, but irradiating to the contralateral hemithorax.

Blood samples were drawn for a complete blood count $(\mathrm{CBC})$, coagulation testing, and biochemistry profile, which consisted of creatinine, BUN, gamma-glutamyltransferase, and alanine aminotransferase. Prothrombin time and activated partial thromboplastin time were within the normal reference range, but the $\mathrm{CBC}$ showed microcytosis, lymphopenia, and hyperproteinemia. Also, elevated alanine aminotransferase and BUN were identified.

Because of the murmur, further exams were requested. On the echocardiogram, we observed a subvalvular aortic stenosis, which resulted in concentric remodeling of the left ventricle (Figure 2) and a mild left atrial dilation. The Doppler study showed a high velocity $(2.77 \mathrm{~m} / \mathrm{s})$ turbulent flow along the left ventricular outflow tract. However, with a pressure gradient of only $30.7 \mathrm{mmHg}$ between the left ventricle and the aorta, the stenotic lesion was classified as mild. Also, the thoracic radiography unveiled cardiomegaly (Figure 3), which was mostly characterized by a craniodorsal cardiac enlargement (between 11-12 $\mathrm{h}$ in the right lateral projection and between $12-1 \mathrm{~h}$ in the ventrodorsal film).

Once the echocardiographic and clinical characteristics were put together, a tentative diagnosis of arterial thromboembolism secondary to subaortic stenosis was established. The recommended therapy included atenolol $(6.25 \mathrm{mg} / \mathrm{cat} \mathrm{PO}, \mathrm{q} 24 \mathrm{~h})^{1}$, clopidogrel (18.7 mg/cat PO, q24h $)^{1}$, enoxaparin (1 mg/kg SC, $\mathrm{q} 24 \mathrm{~h})^{2}$, methadone $(0.2 \mathrm{mg} / \mathrm{kg} \mathrm{IM}, \mathrm{q} 8 \mathrm{~h})^{3}$ and amoxicillin + potassium clavulanate $(20 \mathrm{mg} / \mathrm{kg} \mathrm{SC}, \mathrm{q} 12 \mathrm{~h})^{4}$. Additional recommendations included physical therapy on the hindlimbs as well as monitoring heart rate and blood pressure every $2 \mathrm{~h}$ in the first day, and every $6 \mathrm{~h}$ thereafter during hospitalization.

Seven days later, the cat was depressed, extremely lethargic, and did not respond to therapy at all. Also, necrosis was documented on the hindlimb paws. Therefore, in face of the unfavorable prognosis, the owners opted for euthanasia.

\section{DISCUSSION}

Cats with cardiomyopathy have an increased risk for developing arterial thromboembolism. The dilated left atrium causes blood stasis and, because of the augmented sensitivity of platelets to serotonin, they aggregate and increase the likelihood of thrombi formation. While some thrombi remain within the heart, usually in the left atrial appendage, others may dislodge and follow blood flow to the aortic trifurcation down in the abdomen. That obstruction impairs blood flow to its tributaries such as the iliac and femoral arteries, which are involved with the hind limbs perfusion [9].

In our patient, the concentric myocardial hypertrophy may be attributable to pressure overload owing to the narrowed left ventricular outflow tract. This fact likely increased left ventricular filling pressure and resulted in left atrial dilation, which eventually triggered blood stasis and endothelial lesions. Finally, there was platelet aggregation and the thrombus was formed. The most remarkable abnormality found in the physical examination of cats with aortic stenosis is the ejection-type cardiac murmur. Sometimes, this is the only documented finding, since clinical signs may not be overt whenever mild lesions are present $[1,5]$. 
The confirmation of thromboembolism begins with the patient history and physical examination. Hind limb paralysis together with absent or reduced femoral pulses are the most frequently observed signs [9]. To confirm the diagnosis, however, ancillary exams may be necessary. Either an abdominal ultrasonography with flow mapping (Doppler) or an angiography may show the exact point of obstruction in arterial blood flow towards the limbs. Also, thromboelastography and $D$-dimer quantification may aid in the confirmation of a thrombotic event $[3,7]$. In the cat reported here, the diagnosis was mostly based on the clinical characteristics. The clinical signs presented by the patient, which included Pain, Pallor, Pulseless, Poikilothermy and Paralysis (the five P), are all ascribed to tissue ischemia and are considered classic in cases of thromboembolism [7]. All those findings in association with a documented cardiac disease, which is known to trigger the development of thrombi in cats, were relevant to determine the tentative diagnosis in this patient.

The two-dimensional echocardiography undertaken in this patient showed left ventricular concentric remodeling and a subaortic stenotic lesion, which was characterized as a hyperechoic and fixed structure causing the obstruction of the outflow tract [6]. Also, the Doppler study found an increased peak velocity $(2.7 \mathrm{~m} / \mathrm{s})$ across the left ventricular outflow tract, suggesting obstruction. Nonetheless, because the calculated pressure gradient was lower than $40 \mathrm{mmHg}$, the stenosis was deemed mild [4,5]. Another remarkable characteristic of this disease is the post-stenosis dilation, which was documented in this patient as a bulge in the ventrodorsal thoracic radiography at the 12-1 h position [1].

Medical management with $\beta$-blockers is recommended to reduce myocardial oxygen requirement, therefore decreasing the frequency and magnitude of arrhythmias [4]. Since stenotic lesions are a trigger for endocarditis, antibiotics are indicated to prevent its occurrence [8]. Also, the most fundamental part of therapy is the prevention of thrombi formation. In our patient, both heparin and clopidogrel were prescribed for that reason [2]. Finally, because of the painful nature of thromboembolism, it is critical to give analgesics to the cat especially in the first $24-36 \mathrm{~h}$ past the embolic event [9].

Cats with severe stenotic lesions (pressure gradient $>100-125 \mathrm{mmHg}$ ) usually carry a bad prognosis, contrasting with our patient in which only a mild stenosis was documented. However, having developed aortic thromboembolism absolutely changed the prognosis for this cat [2].

Although aortic stenosis is an uncommon condition in cats, its occurrence should be considered

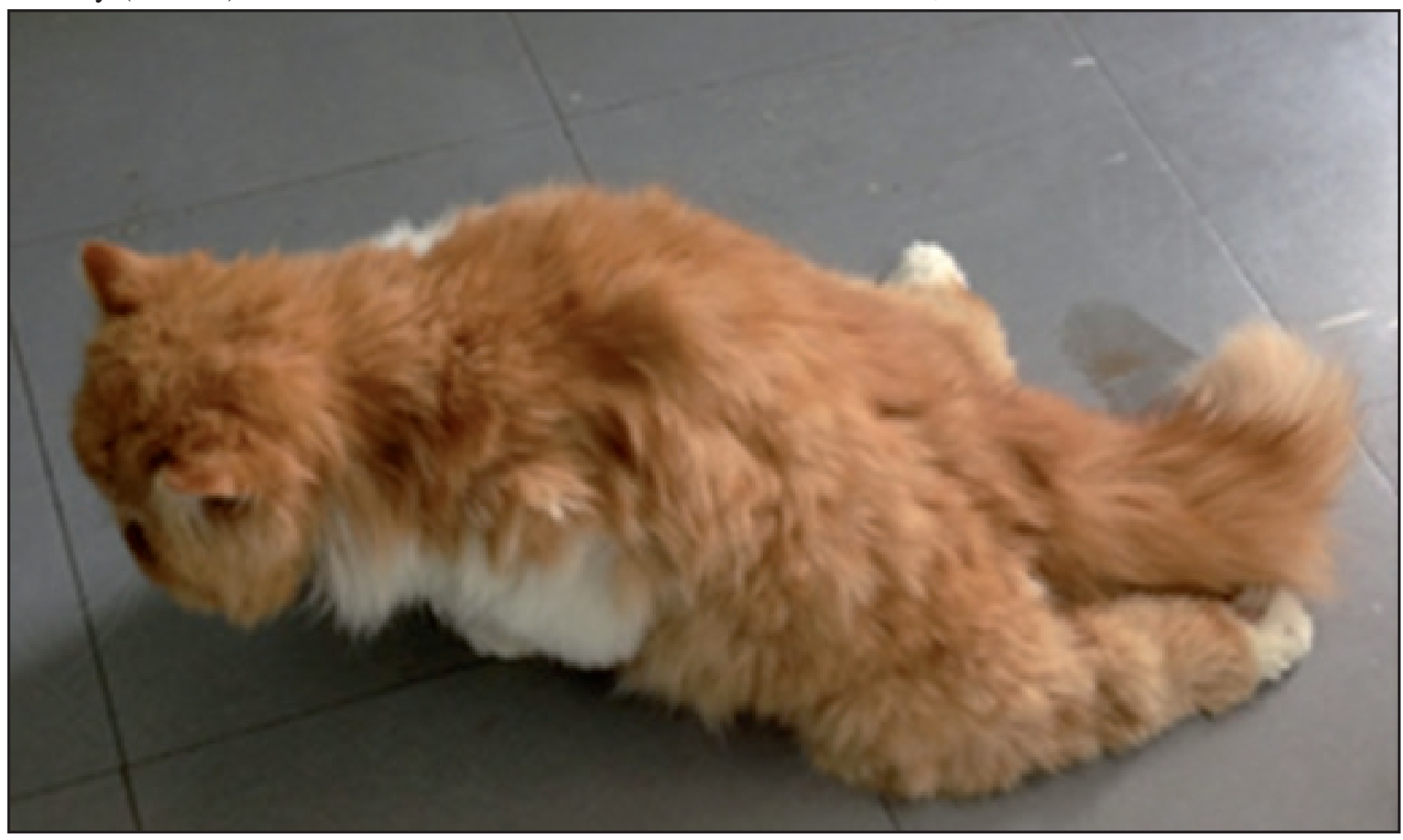

Figure 1. Hindlimbs paralysis in a 7-month old Persian kitten with arterial thromboembolism secondary to subaortic stenosis. 
A.M. Ferreira, S.T.O. Stedile, V.B.C. Silva \& M.G. Souza. 2018. Arterial Thromboembolism Secondary to Subaortic Stenosis in a Persian Kitten.
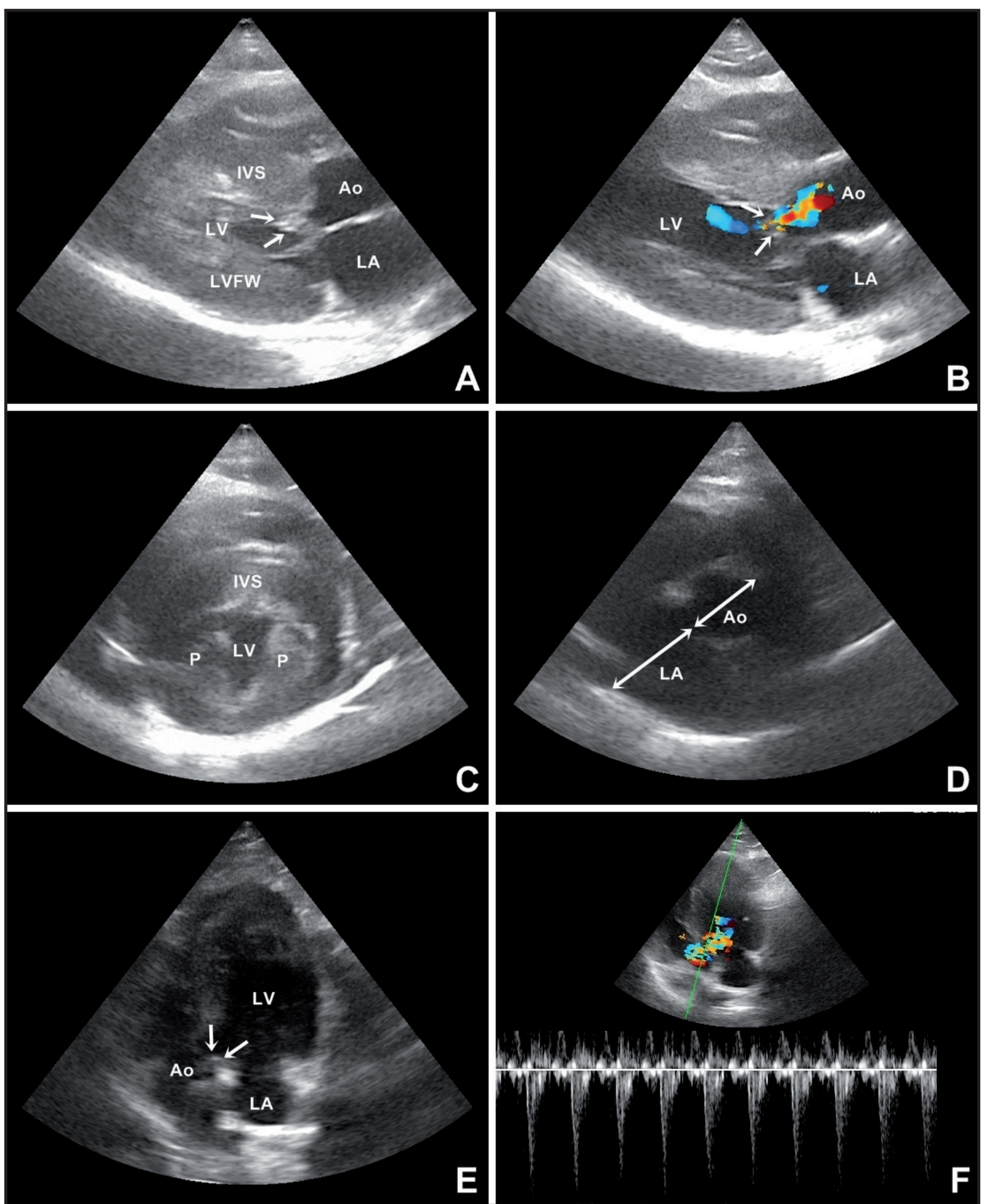

Figure 2. Transthoracic echocardiography obtained in a 7-month old Persian kitten. A- Longitudinal image of the heart showing narrowing of the left ventricular outflow tract due to a subvalvular fibrous ring (arrows); B- Turbulent blood flow caused by the narrowed left ventricular outflow tract (arrows); C- Concentric myocardial hypertrophy seen on a transverse view of the heart; D- Trasnsverse view of the heart depicting mild left atrial dilation (the arrows show the comparison of the left atrial dimension with the aortic diameter); E- Apical five chamber image showing a rigid, hyperechoic structure (arrows) located at the left ventricular outflow tract; and F- Doppler study of the left ventricular outflow tract showing a turbulent flow with increased peak velocity $(2.7 \mathrm{~m} / \mathrm{s})$. Ao: aorta, AE: left atrium, VE: left ventricle, SIV: interventricular septum, PLVE: left ventricular free wall; P: pappilary muscle. 


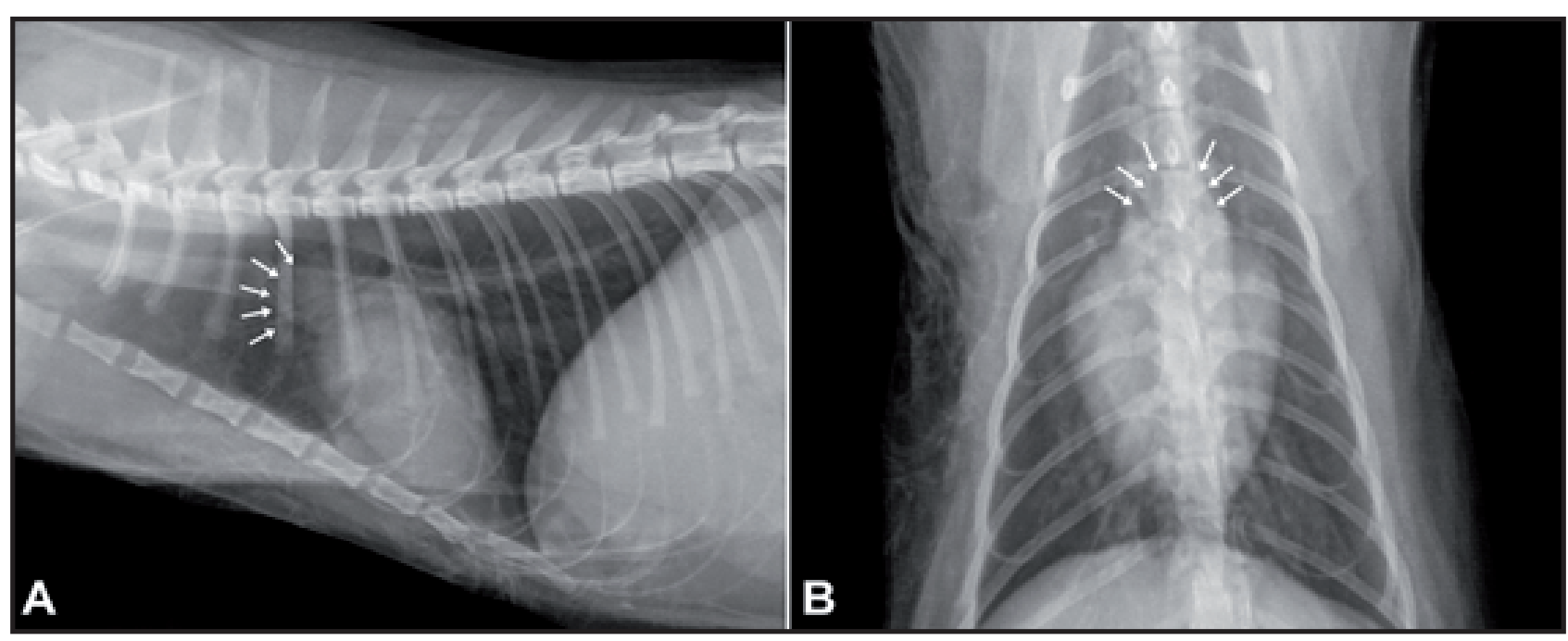

Figure 3. Radiographic images of a 7-month old Persian kitten of right lateral (A) and ventrodorsal (B) evidencing craniodorsal bulging in a region of aortic arch (arrows), whose main differential diagnosis was subaortic or aortic stenosis.

as differential diagnosis whenever young patients are admitted with a cardiac murmur. If the diagnosis is confirmed, the patient will need periodical re-evaluations due to the possibility of complications such as arterial thromboembolism. This condition carries a bad prognosis. In this case, it was responsible for the decline in clinical condition which eventually was crucial for the owner opting to euthanize the cat.

\section{MANUFACTURERS}

${ }^{1}$ Medley Indústria Farmacêutica. Louveira, SP, Brazil.

${ }^{2}$ Sanofi-Aventis. São Paulo, SP, Brazil

${ }^{3}$ Laboratório Cristália. Itapera, SP, Brazil.

${ }^{4}$ Norbrook do Brasil Produtos Veterinários e Farmacêuticos Ltda. São Paulo, SP, Brazil.

Declaration of interest. The authors report no conflicts of interest. The authors alone are responsible for the content and writing of the paper.

\section{REFERENCES}

1 Abbott J.A. 2006. Segredos em cardiologia de pequenos animais. Porto Alegre: Artmed, 480p.

2 Figueroa L.A., Paz R.M., Díaz D.C. \& Dávila R.F. 2014. Tromboembolismo aórtico felino: relato de caso. Revista de Investigaciones Veterinarias del Perú. 25(3): 438-443.

3 Marschner C.B., Bjørnvad C.R., Kristensen A.T. \& Wiinberg B. 2010. Thromboelastography results on citrated whole blood from clinically healthy cats depend on modes of activation. Acta Veterinaria Scandinavica. 52(38): 1-5.

4 Norsworthy G.D., Grace S.F. \& Crystal M.A. 2003. O paciente felino - tópicos essenciais de diagnóstico e tratamento. 2.ed. São Paulo: Manole, 815p.

5 Sousa M.G., Pascon J.P.E., Brum A.M., Santos P.A.C. \& Camacho A.A. 2008. Severe aortic stenosis in a Persian kitten. Revista Portuguesa de Ciências Veterinárias. 103(567-568): 229-232.

6 Stepien R.L. \& Bonagura J.D. 1991. Aortic stenosis: clinical findings in six cats. The Journal of Small Animal Practice. 32(7): 341-350.

7 Tithof P.K., Rebhun W.C. \& Dietze A.E. 1985. Ultrassonographic diagnosis of aortic-iliac thrombosis. The Cornell Veterinarian. 75(4): 540-544.

8 Ware W.A. 2015. Doenças cardíacas congênitas. In: Couto N.W. \& Nelson C.G. (Eds). Manual de medicina interna de pequenos animais. 5.ed. Rio de Janeiro: Elsevier, pp.101-103.

9 Ware W.A. 2015. Doenças tromboembólicas. In: Couto N.W. \& Nelson C.G. (Eds). Manual de medicina interna de pequenos animais. 5.ed. Rio de Janeiro: Elsevier, pp.201-208. 